\title{
Review \\ Kinetic Modeling of Advanced Oxidation Processes Using Microreactors: Challenges and Opportunities for Scale-Up
}

\author{
Danilo Russo $^{+} \mathbb{D}$ \\ Dipartimento di Ingegneria Chimica, dei Materiali e della Produzione Industriale, Università degli Studi di Napoli \\ "Federico II", Piazzale Vincenzo Tecchio 80, 80125 Napoli, Italy; danilo.russo3@unina.it or dr473@cam.ac.uk \\ † Present address: Department of Chemical Engineering \& Biotechnology, University of Cambridge, \\ Philippa Fawcett Drive, Cambridge CB3 0AS, UK.
}

check for

updates

Citation: Russo, D. Kinetic Modeling of Advanced Oxidation Processes Using Microreactors: Challenges and Opportunities for Scale-Up. Appl. Sci. 2021, 11, 1042. https://doi.org/ 10.3390/app11031042

Academic Editor: Bart Van der Bruggen

Received: 30 December 2020

Accepted: 21 January 2021

Published: 24 January 2021

Publisher's Note: MDPI stays neutral with regard to jurisdictional claims in published maps and institutional affiliations.

Copyright: (C) 2021 by the author. Licensee MDPI, Basel, Switzerland. This article is an open access article distributed under the terms and conditions of the Creative Commons Attribution (CC BY) license (https:/ / creativecommons.org/licenses/by/ $4.0 /)$.

\begin{abstract}
With the increasing number of recalcitrant pollutants in wastewater treatment plants, there will be a stringent need for rapid and convenient development of tertiary treatment processes such as advanced oxidation processes (AOPs). Microreactors offer a great opportunity for ultrafast and safe intrinsic kinetic parameters determination, by-products identification, and ecotoxicity assessment. Despite the considerable potential of these devices, they have been mostly used for catalyst screening or pseudo-first order kinetics determination, not allowing for knowledge transfer across scales. This work offers an overview of the adoption of micro- and photo-microreactors for intrinsic kinetics investigations in the field of AOPs to guide future research efforts.
\end{abstract}

Keywords: photoreactors; water; kinetic modeling; photocatalysis; ozonation; Fenton; intrinsic kinetics; AOP; micropollutants; wastewater treatment

\section{Introduction}

Mass consumption of a wide range of new chemicals, from additives and detergents to pharmaceutical and illicit drugs, results in the presence of a large number of pollutants, metabolites, and intermediates in wastewater and, consequently, in surface water, especially in densely populated urban areas [1,2]. In most cases, these compounds have unknown eco-toxicological effects on the aquatic environment and public health $[3,4]$.

Advanced oxidation processes (AOPs) are widely recognized as effective technologies for the removal of harmful compounds in wastewater [5,6]. The great interest shown in the literature can be ascribed to their capability of completely mineralize recalcitrant compounds that are not easily degraded in conventional water treatment $[7,8]$. This is due to the formation of highly reactive, non-selective hydroxyl radicals that can completely oxidize chemicals to $\mathrm{CO}_{2}$, water, and inorganics [7].

Studying AOPs' kinetics and degradation mechanisms of organics is of crucial importance in the design of novel or better-performing reactors and in their optimization [9]. This is usually realized through the estimation of intrinsic kinetic parameters in order to estimate the necessary treatment time [9-11]. Especially for heterogeneous catalytic systems, both immobilized and dispersed, different configurations can only be bridged by light-dependent intrinsic kinetics [12]. Identification of reaction intermediates and their acute and chronic toxicity is also essential, considering that these can help to develop more detailed kinetic models [13-15], and they are often even more toxic than their parent compounds [8,16-18]. As a result, the effective design of treatment plants and residence times has to ensure their transformation to harmless molecules or, where possible, complete removal of both parent compounds and intermediates [19]. In this sense, traditional studies make use of lab-scale batch reactors, usually in the range of 0.5-5 L, to estimate kinetic parameters and collect samples for further MS analysis and toxicity tests $[7,20,21]$. However, lab-scale reactors suffer from several limitations. Relatively large 
volumes require higher amounts of compound and they present significant spatial gradients of variables and, consequently, higher treatment times, usually resulting in long and resource-demanding experimental campaigns. When photocatalytic and/or heterogeneous systems are investigated, mass transfer limitations, light absorption of solid suspensions and organics, non-uniform light intensity, and complex hydrodynamics represent further complications; in traditional batch reactors, large gradient, and the consequent use of volume-averaged properties can affect the estimation of intrinsic kinetic parameters and, as a result, their adoption to predict degradation across scales [12].

The use of microreactors, with dimensions in the range of 10-1000 $\mu \mathrm{m}$, represents a promising technology for the estimation of intrinsic parameters and mechanistic studies [22-25]. Among the advantages they offer are (i) faster degradation kinetics, resulting in time-efficient experimental campaigns-this also allows to use cheap low-voltage lamps or light-emitting diodes (LEDs) systems [26] more efficiently when photocatalytic systems are investigated; (ii) reduced size-in addition to compactness and intrinsic safety, these devices present lower spatial gradients of the physical variables, e.g., light intensity and concentrations, resulting in simplified models and more precise parameter estimation [12]; (iii) reduced volumes with economic advantages in terms of amount of required materials and reduced amount of produced waste [23]; (iv) continuous flow operations, with the possibility of automation and direct coupling with analytical instruments; this allows to save additional time and resources by carrying out experiments in a fully automated fashion [27-29]; (v) adoption of very small amounts of immobilized solid catalysts and efficient gas-liquid and liquid-liquid mass transfer, depending on the investigated system [12,22].

In most papers in the field of microreactors for wastewater treatment, they have been used to rapidly screen different reactive systems, study the effect of operative parameters, and compare performances [30-34]. From a kinetic point of view, this is usually carried out by estimating pseudo-first order or apparent kinetic constants [31,35-41]. Although this approach enables a rapid screening of competing materials under the same adopted conditions, pseudo-constants are dependent on the specific adopted device and conditions and do not allow any knowledge transfer across scales for the simulation and design of larger plants [12]. Although some authors suggested the possibility of direct use of these devices for water treatment by numbering up units [25,42], this seems a fairly unrealistic and antieconomic scenario, with very few possible niche applications in the treatment of small volumes of water for specific applications. Only a limited number of papers have addressed the use of microreactors for the estimation of intrinsic parameters and mechanism identification, which can be used for the scale-up of AOPs for wastewater treatment, which, in fact, is the most promising application [9,11,12,23,43-54]. In this sense, there is still extensive room for improvement and exploitation of this technology for the design and scale-up of such tertiary treatments.

The aim of this paper is a critical review of the literature dealing with the adoption of microreactors for the estimation of intrinsic kinetic parameters of AOPs for wastewater treatment in order to give some perspectives in the field and guide future research efforts. Papers discussing the relative influence of different transport phenomena on the estimation of degradation conversion are also taken into account. All papers investigating adopted materials and fabrication techniques of microreactors, as well as the ones dealing with mere comparisons of reactive systems and the estimations of pseudo-kinetic constant, have already been extensively reviewed $[25,55,56]$ and are out of the scope of the present paper.

\section{Heterogeneous Systems: $\mathrm{TiO}_{2}$ Photocatalysis}

The estimation of intrinsic kinetic parameters requires models capable of capturing the relative influence on the measured outputs of different phenomena occurring in microreactors, namely chemical reactions, adsorption, light absorption, mass transfer limitations between the phases and within each phase, fluid dynamics, etc. Selection of the right model is of crucial importance and it is highly dependent on the specific process investigated. 
Photocatalytic processes using $\mathrm{TiO}_{2}$ are among the most commonly investigated heterogeneous photocatalytic systems. Despite the great variety of devices, materials, and deposition techniques, these microreactors present some common characteristics and mechanisms. The general scheme of a photocatalytic microreactor for degradation studies is reported in Figure 1.
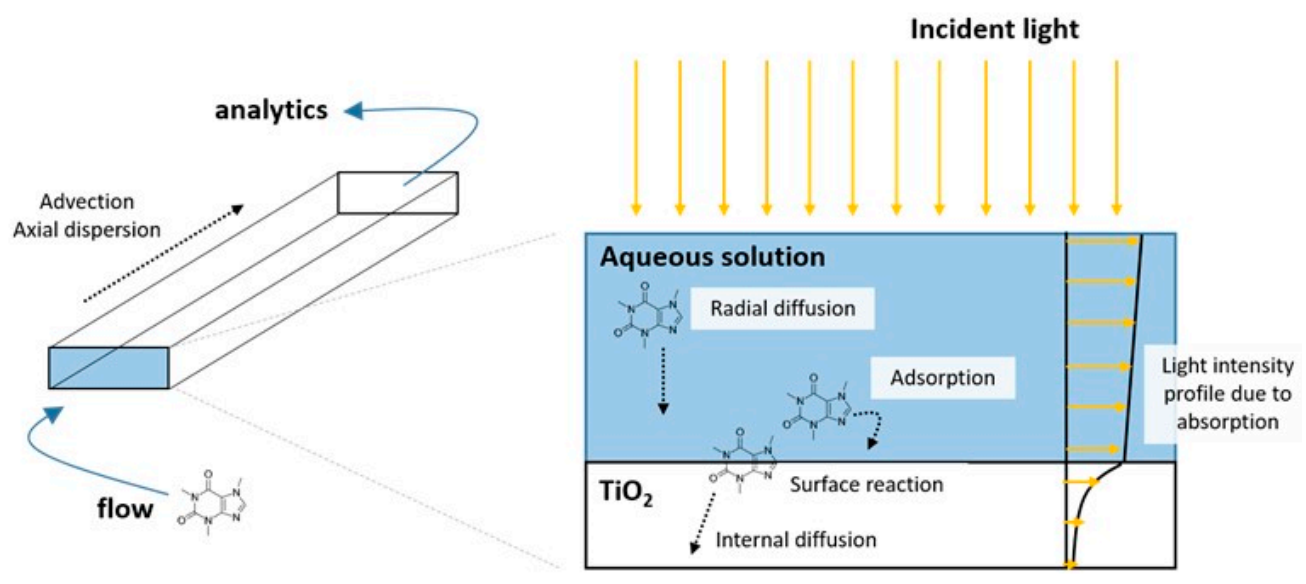

Figure 1. Main mechanisms controlling pollutant degradation in immobilized catalyst microreactors.

The internal surface of the microchannel is usually covered with a thin layer of photocatalytic material. The light is often irradiated on the opposite side, where no catalyst is present. In this case, the main factors controlling the degradation are (i) adsorption of species on the catalytic surface and surface reaction; (ii) advection and diffusion of the species in the liquid phase; (iii) diffusion of the species in the solid catalyst for porous materials; (iv) light absorption of the liquid solution, containing the pollutants and degradation products; $(v)$ light absorption of the solid catalytic layer, resulting in the generation of photoexcited electron/hole pairs and oxidizing species.

\subsection{Reactor Modeling}

Most papers dealing with reactions occurring over immobilized $\mathrm{TiO}_{2}$ [47,49,57-59] adopt a Langmuir-Hinshelwood reaction mechanism for the study of intrinsic reaction kinetics, expressing the reaction rate of the generic compound $A$ as

$$
r=\frac{k K_{a d}[A]_{\text {surf }}}{1+K_{a d}[A]_{\text {surf }}}
$$

where $k$ is the intrinsic kinetic constant for the surface reaction of adsorbed $A ; K_{a d}$ is the adsorption equilibrium constant of $A$ on the catalytic surface, under the Langmuir adsorption assumptions, and $[A]_{\text {surf }}$ is the concentration of $A$ at the liquid/solid interface. The $[A]_{\text {surf }}$ value is usually lower than the bulk liquid concentration because of the presence of mass transfer limitations. At a steady state, this gives:

$$
\frac{k K_{a d}[A]_{\text {surf }}}{1+K_{a d}[A]_{\text {surf }}}=k_{g} a\left([A]_{\text {bulk }}-[A]_{\text {surf }}\right)
$$

where $k_{g}$ is the global mass transfer coefficient, which is a function of the Schmidt and Reynolds numbers and, therefore, of the physical properties of the fluid, the velocity profile inside the microreactor channel, the geometry of the channel, and the diffusion coefficient of $A$ in the liquid phase. The general theoretical approach to solve the problem would be to find a semi-empirical correlation between the non-dimensional Sherwood, Schmidt, and Reynolds numbers to express $k_{g}=f(S c, R e)$ and then couple the semiempirical equation with Equations (1) and (2) for the estimation of the intrinsic kinetic 
parameter $k$. The procedure is, in general, a lengthy process that relies on accurate estimation of diffusion coefficients, often not available in the literature. A common correlation for laminar flow in microchannels is [24]:

$$
S h=\frac{k_{g} d_{H}}{L}=7.54\left(1+0.095 \frac{d_{H}}{L} R e \cdot S c\right)^{0.45}
$$

In the context of water treatment studies, a constant value for water viscosity is commonly used, without considering any possible effect of small diameters and water matrices.

Recent direct use of Equations (1)-(3) for the determination of intrinsic parameters for the degradation of pollutants in water is proposed by Zhan et al. [24]. For this aim, Rhodamine B degradation was studied in a microchannel over immobilized $\mathrm{TiO}_{2}$. The kinetic parameters were determined in a macroscopic batch reactor with immobilized $\mathrm{TiO}_{2}$ and then the results were validated using the microreactor modeled according to Equations (1)-(3), with a reported maximum error of $20 \%$ in the observed conversion. Another study [57] also followed the same general approach, using a different correlation for rectangular microchannels.

However, most papers make direct use of Equation (1) in the following form:

$$
r=\frac{k_{a} K_{a d}[A]_{b u l k}}{1+K_{a d}[A]_{b u l k}}
$$

where $k_{a}$ is generally known as an apparent kinetic constant and it does not take into account the effect of mass transfer limitations on the observed overall reaction rate. Of course, Equation (4) reduces to Equation (1) under kinetic regime assumption. In fact, if mass transfer is much faster than intrinsic reaction rate, $k_{g} \gg k$, as a result, $[A]_{\text {bulk }}=[A]_{\text {surf }}$ and $k_{a}=k$. Apparent constants estimation by Equation (4) is a common practice in the literature to screen different materials and compare the results for different target compounds. However, these constants are dependent on the specific adopted device, lamp source, and operating conditions, and they cannot be used to translate models to full scale and to design and optimize real water treatment systems. The few papers addressing this point tackle the estimation of $k$ values using two main approaches: $(i)$ design devices and adopt conditions so that radial mass transfer limitations can be considered negligible or (ii) describe the system with a full set of equations taking into account mass transfer limitations and solve them numerically. The first approach is more common and it is based on of the main advantages of microreactors. Their radial dimension, in fact, is often small enough to consider characteristic time of radial diffusion as much lower than residence time, so that diffusive mass transfer can effectively equalize the concentration along the radius. However, this assumption is not often adequately justified. Tsuchiya et al. [60], for example, used a fused silica circular capillary with immobilized $\mathrm{TiO}_{2}$ for the removal of several dyes from water, and they claim that mass transfer limitations are negligible for an internal diameter of $530 \mu \mathrm{m}$, without giving any indication of the adopted length and flow rates and of the relative order of magnitude of the different transport phenomena in the system. On the other hand, in a recent study, Satuf et al. [44] report a fully characterized microdevice, giving a mathematical derivation for the estimation of intrinsic kinetic parameters when the reactor is operated under a kinetic regime, i.e., in the absence of external mass limitations. However, the complete mathematical derivation is only valid for reactions following a first-order rate law. Specifically, they verified assumptions and a model for the degradation of clofibric acid using computational fluid dynamics (CFD) simulations in OpenFOAM and experimental results in a scaled-up system.

Different non-dimensional groups have been proposed in the literature for the evaluation of the relative significance of mass transfer mechanisms and intrinsic reaction kinetics. In the field of microreactors for wastewater treatment, these are reported by de Sá et al. [42] as the second Damkohler number $D a_{I I}$, defined as the ratio of the rate of a chemical reaction to diffusive mass transfer rate. 
In particular, Gorges et al. [47] report the following expression for Langmuir-Hinshelwood kinetic laws with apparent reaction rate constant $k_{a}$ :

$$
D a_{I I}=\frac{\text { reaction rate }}{\text { diffusive mass transfer rate }}=\frac{k_{a}}{\frac{k_{g} a}{K_{a d}}+k_{g} a[A]_{\text {bulk }}}
$$

Considering that a laminar flow regime is always present in microreactors and, for low flow rates, the Sherwood number approaches the asymptotic value of 3.66 [48],

$$
D a_{I I}=\frac{k_{a} d_{H}}{3.66 a \mathfrak{D}\left(K_{a d}^{-1}+[A]_{b u l k}\right)}
$$

Equation (6) enables to estimate $D a_{I I}$ once the interfacial area per unit volume $a$ and the molecular diffusion coefficient $\mathfrak{D}$ can be evaluated. The term $d_{H}$ is the hydrodynamic diameter. It is important to stress that this asymptotic value of the Sherwood number is different from the one reported in Equation (3).

As a general rule of thumb, a kinetic regime can be assumed if $D a_{I I}<0.1$. In addition to the relative magnitude of molecular diffusion and intrinsic reaction, the influence of advection is also of crucial importance in modeling the concentration profile along the length of microreactors and, therefore, the dependence of the measured concentration at the outlet of the reactor on residence time. In this case, the ratio between the characteristic time of diffusion and advection is given by the non-dimensional Peclet number $P e$.

$$
P e=\frac{u L}{\mathfrak{D}}
$$

where $u$ is the characteristic mean bulk velocity, defined as the ratio between the flow rate and the cross-sectional area, and $L$ is the characteristic length of the problem, usually the length of the reactor. However, it is important to stress that in the specific case of microreactors, characterized by exceptionally high aspect ratios $\left(L / d_{H}\right)$, it can also be useful to define the Peclet number by comparing the efficiency of the diffusive equalization in the radial direction with the one of advection along the length of the reaction [42]. In this case, the definition of $P e$ becomes:

$$
P e^{\prime}=\frac{u d_{H}^{2}}{\mathfrak{D} L}=P e\left(\frac{d_{H}}{L}\right)^{2}
$$

In the rare situation in which $P e$ and $P e^{\prime}$ are both $\ll 1$, molecular diffusion is very efficient in equalizing concentrations in bulk liquid, in both the radial and longitudinal dimensions of the reactor, within the residence time. The occurrence can only be verified when very short reactors or extremely low flow rates are adopted; if $D a_{I I}$ is $<0.1$, there are ideally no spatial concentration gradients; if $D a_{I I} \gg 1$, the reaction rate is even faster than molecular diffusion with respect to the space-time in the reactor, and therefore, the reactor can be considered oversized at the adopted flow rate.

If $P e \gg 1$ and $P e^{\prime} \ll 1$, diffusion can efficiently equalize concentrations in the radial direction, but advection is the only significant mechanism along the length of the capillary; depending on the relative order of magnitude of the non-dimensional numbers and the velocity profile, a plug flow reactor or an axial dispersion model might be adequate to describe bulk liquid. In this condition, when $D a_{I I}$ is $<0.1$, no radial concentration gradients will be present, but the time-space in the reactor can be low compared to the diffusion and reaction characteristic times, and low conversion can be observed; when $D a_{I I}$ is larger than unity, mass transfer limitations have to be considered around the solid layer.

If $P e$ and $P e^{\prime}$ are both $\gg 1$, an axial dispersion model or a pure convection laminar model might be adequate to describe bulk liquid, depending on the situation. Characterizing non-ideal flow patterns using a tracer can help to discriminate between different situations; in this case, if $D a_{I I}$ is $>1$, then mass transfer limitations in the ra- 
dial direction will cause a concentration gradient in the proximity of the catalytic surface; if $D a_{I I}$ is $<0.1$, very low conversion will be observed since most of the pollutants will reach the outlet of the reactor without coming into contact with the catalytic surface where, in addition, the reaction is extremely slow. This is schematized in Scheme 1.

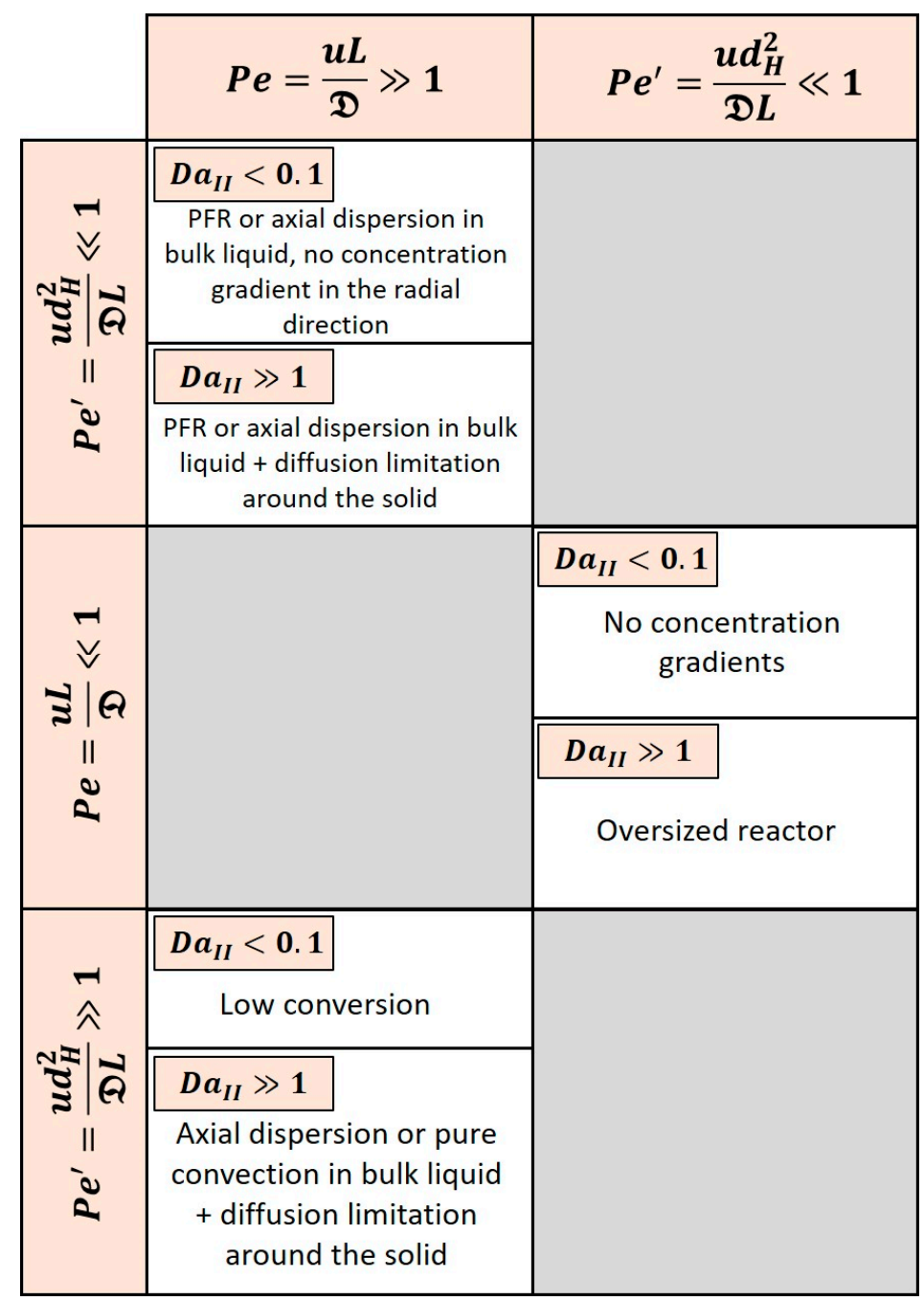

Scheme 1. Most common situations in immobilized photocatalytic microreactors and their dependence on non-dimensional analysis.

When a kinetic regime cannot be assumed or estimating non-dimensional groups a priori is not easy, different approaches have been used. Corbel et al. [49] examined the degradation of salicylic acid using a 70-mm-long channel, with a cross-sectional rectangular section of about $1 \times 0.5 \mathrm{~mm}$, with immobilized $\mathrm{TiO}_{2}$ and low flow rates of the order of $2 \mathrm{~mL} \cdot \mathrm{h}^{-1}$. Navier-Stokes equations were coupled with Equation (2) for the mass transfer limitations and the Langmuir-Hinshelwood rate law and solved using the numerical software COMSOL. Multiphysics The simulations showed a significant concentration gradient in both the radial and longitudinal directions, which is in line with the fact that the calculated apparent kinetic constants were a function of the adopted flow rate.

In a more recent study, Suhadolnik et al. [9] investigated the degradation of Reactive Red 106 dye in a photo-electrocatalytic microreactor with a $\mathrm{TiO}_{2}$ (anatase) anode. In this case, the photo-microreactor consisted of a cylindrical UV transparent poly(methyl methacrylate) glass channel. The microreactor was chosen for the determination of the intrinsic kinetics of decomposition because of the simplicity of a detailed model development com- 
pared to a scaled-up batch system. A detailed model was used for solving the convectiondiffusion equation for the transport in the bulk of the reactor:

$$
\frac{\partial[A]}{\partial t}+\nabla \cdot(-\mathfrak{D} \nabla[A]+v[A])=0
$$

considered at steady state $\left(\frac{\partial[A]}{\partial t}=0\right)$ in the cylindrical coordinates and where $v$ is the velocity profile in laminar flow, using the following boundary conditions:

$$
\begin{gathered}
-\mathfrak{D} \frac{\partial[A]}{\partial r}=-r_{\text {reaction }} \text { at the walls } \\
\frac{\partial[A]}{\partial r}=0 \text { at the center of the channel }
\end{gathered}
$$

The reaction rate was expressed, for the photo-electrochemical case, as a function of the light intensity, the current, and the concentration of the reagent through the adoption of an intrinsic kinetic constant. The kinetic parameters were estimated through a regression of experimental data. The results of the model in this case showed that there was no significant concentration gradient along the radius of the reactor, confirming kinetic control. More interestingly, the so-obtained kinetic parameters under the kinetic regime were then integrated in a more complex model to design and successfully predict the behavior of a scaled-up system with a volume 700 times higher than the one of the adopted microreactor.

Charles et al. [57] used a tracer to characterize the flow pattern in the liquid phase and adopted an axial dispersion model accordingly. They also provide a useful simplified analytical expression for conversion based on their assumption.

Finally, one of the most complete detailed kinetic modeling examples for photomicroreactors with immobilized $\mathrm{TiO}_{2}$ was presented by Visan et al. [12]. To date, this is the only accurate modeling of such a system, simultaneously taking into account diffusion of the reacting species and light-dependent kinetic parameters in the catalytic layer. The adopted microdevice consisted of a 5.96-cm-long rectangular channel with a cross-sectional area of $50 \times 500 \mu \mathrm{m}$. Catalytic layers of commercial $\mathrm{TiO}_{2}$ ranging from 310 to $4000 \mathrm{~nm}$ were deposited in the channel. The device was used to study the degradation of cortisone 21-acetate, a common glucocorticoid with anti-inflammatory properties, and methylene blue, as a reference compound. In this detailed model, the entire channel was divided into two separate domains: the liquid phase and the solid layer. In the flow channel, the dispersion-advection Equation (9) was solved with the following boundary conditions:

$$
\begin{gathered}
\mathfrak{D} \frac{\partial[A]}{\partial y}=0 \text { at the wall } \\
\left.\left.\mathfrak{D} \frac{\partial[A]}{\partial y}\right]_{\text {fluid }}=\mathfrak{D}_{\text {eff }} \frac{\partial[A]}{\partial y}\right]_{\text {solid }} \&[A]_{\text {fluid }}=[A]_{\text {liquid }} \text { at the interface }
\end{gathered}
$$

where $y$ represents the vertical dimension, perpendicular to the longitudinal axes of the channel, and $\mathfrak{D}_{\text {eff }}$ is the effective diffusion coefficient in the porous catalyst. This equation was coupled with the mass balance in the solid catalyst domain:

$$
\mathfrak{D}_{e f f} \frac{\partial^{2}[A]}{\partial y^{2}}+r_{\text {reaction }}=0
$$

where

$$
\mathfrak{D}_{\text {eff }} \frac{\partial[A]}{\partial y}=0 \text { at the wall }
$$

and $r_{\text {reaction }}$ represents the reaction rate, usually following a Langmuir-Hinshelwood model. In this specific study, the authors proved that under the adopted conditions, the intrinsic kinetic followed a first-order rate law in the concentration of the pollutants. In this specific 
case, Equation (14) has a well-known solution, and the concentration profile in the solid catalysts is a known function of the spatial coordinate $y$

$$
[A]=[A]_{\text {interface }} \frac{\cosh \left(\Phi\left(1+\frac{y}{\delta}\right)\right)}{\cosh (\Phi)}
$$

and the Thiele modulus, directly expressed as

$$
\Phi=\delta \sqrt{\frac{k}{\mathfrak{D}_{\text {eff }}}}
$$

where $\delta$ is the thickness of the catalytic layer and $k$ is the first-order kinetic constant. For more complex kinetic laws, Equation (14) must be solved numerically and there is no general functional correlation for any value of the parameters. To take into account the dependence of the kinetic constant on the light intensity and, therefore, the photon flux density in the solid layer, the Nielsen equation was used, based on semiconductor physics:

$$
k=k_{0} I^{\gamma}=k_{0}\left(\frac{\alpha \Phi_{0}}{B p_{0} n_{0} h \omega}\right)^{\gamma} \exp (-\gamma \alpha y)
$$

where $\alpha$ is the absorption coefficient of the catalytic layer, $\gamma$ is the transfer coefficient of the electron transfer process, $\Phi_{0}$ is the incident photon flux density, $h \omega$ is the photon energy, and $B p_{0} n_{0}$ is the equilibrium electron-hole recombination rate. This expression of $k$ is also valid for the intrinsic kinetic constant of the Langmuir-Hinshelwood model [24]. The model was used to describe pollutants' removal in the adopted microdevice, highlighting the important criterion to consider $\mathrm{k}$ independently of the light intensity; Equation (18). Specifically, the photon flux exponential decay can be neglected for layers' thickness lower than a characteristic decay length, calculated as $1 /(\gamma \cdot \alpha)$. The lightindependent model could be also adopted at high photon flux density.

Finally, it is worth mentioning that light scattering of the solid catalyst particles, reported as a critical factor to consider for dispersed batch systems, can be easily neglected for immobilized catalytic layers. For a full discussion of light scattering in this context, the reader can refer to the recent review in [45].

In summary, analogously to what has been reported for the flowing liquid domain, in the catalytic layer, the relative magnitude of the diffusive and reactive phenomena can be evaluated using the Thiele modulus, defined by Equation (19) for intrinsic first-order kinetics. A generalized expression of the Thiele modulus for an $n$-th order reaction is:

$$
\Phi_{\text {gen }}=\frac{V_{\text {cat }}}{A_{\text {ext }}} \sqrt{\frac{(n+1) k[A]_{\text {surf }}^{n-1}}{2 \cdot \mathfrak{D}_{\text {eff }}}}
$$

where $V_{\text {cat }}$ is the volume of the porous layer, $A_{\text {ext }}$ is the exposed surface, $k$ is the intrinsic kinetic constant, and $\mathfrak{D}_{\text {eff }}$ is the effective diffusion coefficient. $\Phi_{g e n}^{2}$ is also known as the Weisz modulus, when $k[A]_{\text {surf }}^{n-1}$ is replaced by the observed reaction rate. In this case, it has also been used for assessing pore diffusion limitations for Langmuir-Hinshelwood rate laws [24]. High values of the Thiele (or Weisz) modulus indicate that the reaction is relatively fast compared to internal diffusion, and as a result, the reagent cannot penetrate in the catalytic layer. On the contrary, low values indicate the absence of internal diffusion limitations. Definition of the Weisz modulus enables faster determinations, since it is based on the evaluation of the observed reaction rate, whereas the Thiele modulus is dependent on the intrinsic kinetic constants, not known a priori. However, the limiting values for the Weisz modulus to distinguish between the different regimes are dependent on the product $K_{a d}[A]_{\text {surf }}$ for Langmuir-Hinshelwood kinetics, which cannot be always easily determined in the presence of external mass transfer limitations. In this case, tailored experiments in the 
absence of external mass transfer limitations can be run for its evaluation. Even when this is not feasible, estimation of the order of magnitude is often possible. A general procedure to guide the model choice for the solid layer is reported in Schemes 2 and 3.

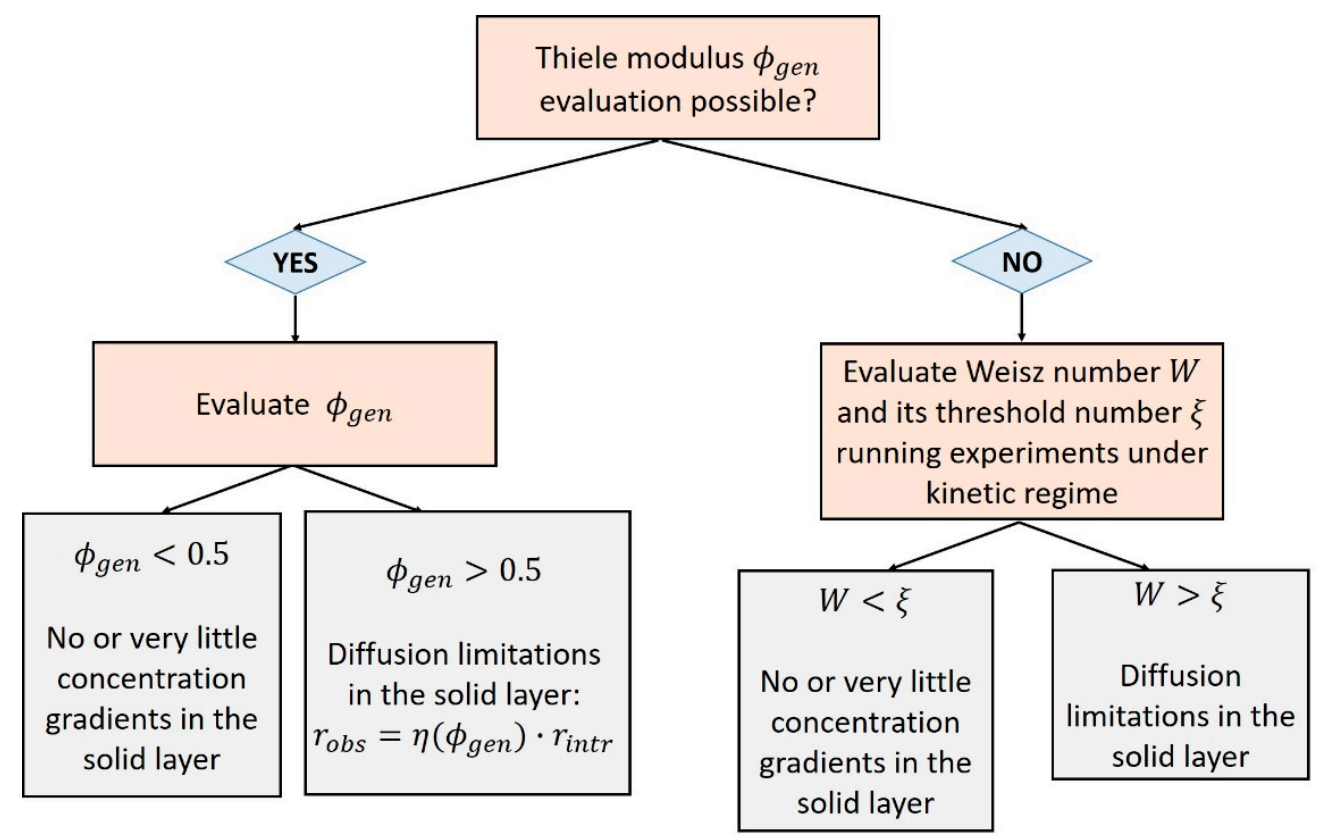

Scheme 2. Mass transfer limitation evaluation in the solid catalytic layer.

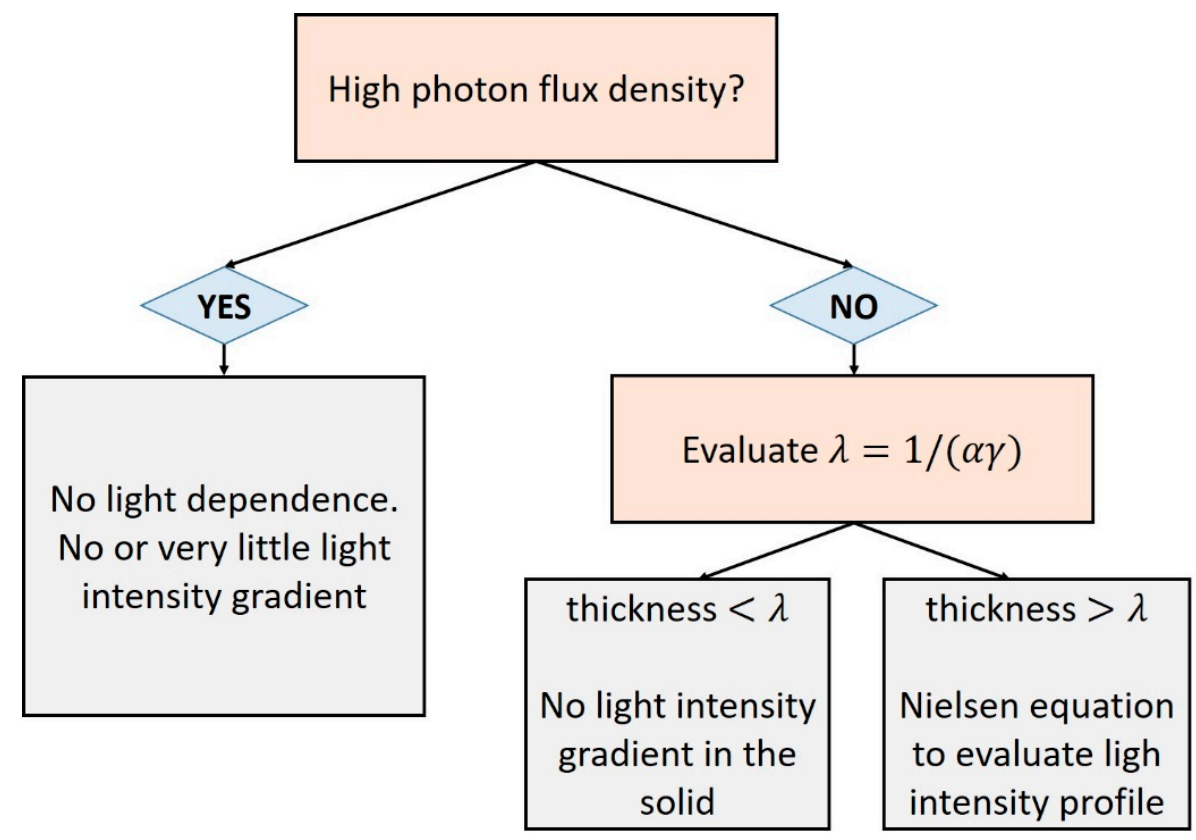

Scheme 3. Light absorption evaluation in the solid catalytic layer.

\subsection{Light Absorption in the Liquid Phase}

One of the main advantages of using microdevices with a reduced optical length is that the light intensity profile in the flowing liquid domain can be considered constant with the height of the channel. However, even in the case of significant light absorbance in the liquid phase, this can be easily modeled according to the Lambert-Beer law without 
any volume-averaged property, as in the case of traditional batch annular reactors with suspended solids. Light intensity is a function of the height $h$ :

$$
I(h)=I_{0} \cdot 10^{-\varepsilon h c}=I_{0} \exp (-2.3 \varepsilon h c)
$$

where $I_{0}$ is the intensity of the light at the exposed microreactor surface, $\varepsilon$ is the molar absorption coefficient of the species in the liquid phase, $c$ is their concentration, and $h$ is the distance from the exposed surface of the reactor. For most devices, the maximum $h$, known as the optical length, is so small that $I \approx I_{0}$ at any given $h$. Even though the photon flux might be considered constant in most common situations, it is not possible to exclude direct photolysis of the pollutants in the liquid bulk occurring at the same time of reaction on the surface of the solid catalytic layer. No papers were found modeling direct photolysis occurring simultaneously to the heterogeneous catalytic reaction. This can be a good approximation when photocatalytic removal is much faster than direct photolysis, which is often the case. However, this assumption is highly dependent on the adopted light source and its emission spectrum and, in general, it should be verified through blank tests in the absence of the photocatalyst [44].

\subsection{The Role of Oxygen}

According to the well-known mechanism for $\mathrm{TiO}_{2}$ photocatalysis, the presence of oxygen plays a key role in the oxidizing process by reacting with photogenerated electrons and reducing electron/hole recombination according to the general scheme:

$$
\begin{gathered}
\mathrm{TiO}_{2} \stackrel{h v}{\rightarrow} h^{+}+e^{-} \\
\mathrm{O}_{2}+e^{-} \rightarrow \mathrm{O}_{2}^{\bullet-} \\
A+h^{+} \rightarrow A_{o x}
\end{gathered}
$$

However, most microchannels are closed systems with respect to oxygen. As a result, oxygen concentration and, therefore, reaction rate can decrease in the channel as the reaction occurs, depending on the adopted conditions. In the field of photo-microreactors for pollutant degradation in water, very few paper address the role of oxygen in intrinsic kinetics determination. Visan et al. [12] ensure that oxygen consumed in the reaction is replaced by using an oxygen-permeable surface of PDMS, a commercial polymeric coat. In the above-mentioned study, Satuf et al. [44] ensure oxygen overpressure in a batch system used as a benchmark, without mentioning how oxygen constant concentration is ensured in the microreactor system.

One of the first studies assessing the role of gaseous oxygen in photocatalytic microreactors for contaminant removal was presented by Lindstrom et al. [48]. In this work, they take advantage of the high surface-to-volume ratio that can be realized in photomicroreactors and the consequent enhancement of mass transfer between phases to saturate oxygen concentration by generating alternating plugs of gas and liquid in the reactor. The results show that the addition of gaseous oxygen dramatically enhanced the removal of methylene blue, demonstrating that there are conditions under which oxygen consumption in the liquid phase does not allow to consider zero-order kinetics with respect to its concentration. More recently, Yu et al. [61] presented a more detailed fluid dynamics modeling of such a system. In their study, it is evident that alternated oxygen bubbles can both increase oxygen concentrations in proximity of the catalytic layer and change the fluid dynamics of the stagnant liquid film covering the solid, increasing its velocity and mixing.

As a general conclusion, oxygen consumption within closed-system microdevices must be properly assessed, and the resulting assumption verified, in order to consider investigations on intrinsic kinetics to be reliable and transferable across scales. 


\subsection{Time to Steady-State Conditions}

A final remark for the use of photo-microreactors for intrinsic kinetic parameter estimation concerns the time to achieve steady-state conditions. All models adopted for kinetic derivations are, in fact, based on the assumptions that light irradiance is constant with time, fluid dynamic conditions are stationary, and an adsorption equilibrium is achieved. There is no general indication of the time needed to achieve steady-state conditions. Good practice would be to test whether the results are time-independent under the typical adopted conditions before planning experimental campaigns. Most light sources also require some time to achieve constant steady-state irradiation and they should always be turned on in advance. As a general rule of thumb, 3-5 times the mean residence time should ensure steady-state fluid dynamics. For adsorption equilibrium, longer times are usually suggested of the order of $1 \mathrm{~h}[24,50]$, although no critical discussion could be found.

\section{Heterogeneous Systems: Electrochemical AOPs}

Electrochemical oxidation for wastewater treatment offers a range of advantages, being robust, reliable, and flexible [62,63]. However, very few studies address the complete modeling of electrochemical oxidation in microreactors. Suhadolnik et al. [46] modeled a coil-type electrocatalytic microreactor with a Ti-O-N anode and a titanium cathode, using the advection-convection equation and a detailed micro-kinetic model. Experimental results and numeric simulations for estimation of the kinetic parameters of phenol degradation were used to assess concentration gradients between the walls of the device at different radial gaps, showing that mass transfer limitations start to be significant for a gap larger than $200 \mu \mathrm{m}$. Khongton et al. [50] presented an interesting comparison between detailed intrinsic kinetic modeling and pseudo-first order observed kinetics for the degradation of diuron, a toxic herbicide, in a microdevice. The microchannel had a rectangular cross-sectional area of $10 \mathrm{~mm} \times 250-750 \mu \mathrm{m}$, depending on the experiment, and a length of $21 \mathrm{~mm}$. The upper and lower walls consisted of two electrodes: a graphite anode and a stainless steel cathode. Degradation was mainly due to hydroxyl radical formation by water dissociation at the anode, under an applied current intensity of $1 \mathrm{~mA}$. The Navier-Stokes equation, the continuity equation, and the advection-convection equation were implemented in the COMSOL platform and coupled with the intrinsic first-order kinetic rate law of the reaction occurring in the liquid phase. This model was used to fit experimental data for different residence times and the results were compared using a simple pseudo-first order model, ignoring mass transfer limitations. The rigorous model showed superior results, but the order of the two kinetic constants was comparable for a channel thickness of $250 \mu \mathrm{m}$, demonstrating very little influence of mass transfer limitations in this configuration. As a result, the simplified model was used to estimate the influence of operating conditions such as $\mathrm{pH}$ and current intensity on the intrinsic kinetic constant. When increasing the channel thickness, the results showed poor predictions of the simplified model, demonstrating that in this case, diffusion of generated hydroxyl radicals into the bulk of the liquid phase has to be taken into account. Unfortunately, no validation of the prediction of the rigorous model was presented under these conditions.

Further research in the field should address the use of microreactors for the investigation of electrochemical AOPs' intrinsic kinetics, validating the presented results in order to (i) define modeling protocols for kinetic estimation in the presence of mass transfer limitations and (ii) better define the design criteria to obtain mass transfer-independent parameters. Despite the great potentiality of deriving kinetic models for such systems, minimizing energy consumption and resource waste, electrochemical AOPs are still preferentially investigated using macroscopic lab-scale reactors.

\section{Heterogeneous Systems: Ozonation}

Microreactors have great potential for the investigation of heterogeneous gas-liquid reactions, i.e., large contact area between the phases, liquid recirculation in slugs, and effective diffusion, resulting in higher and uniform concentrations. However, no papers have 
investigated the intrinsic reaction kinetics of AOPs in the presence of ozone. Two recent studies [64,65] describe interesting devices, but only apparent first-order kinetics have been evaluated: in the first case, an ozone-permeable photocatalytic membrane covered with a thin layer of $\mathrm{TiO}_{2}$ is placed between a gas chamber, containing flowing ozone, and a liquid chamber, irradiated by the incident light. The second is a micro-packed bed reactor, with wastewater and ozone flowing through zirconia/alumina microparticles. The promising preliminary results of these studies show optimal ozone saturation and consequent apparent kinetic constants, three orders of magnitude larger than the ones obtained in traditional lab-scale systems, where mass transfer limitations can be the controlling mechanism. Based on these results, future studies will have to address the fast and accurate determination of intrinsic kinetic parameters and the use of this devices to decouple mass transfer and intrinsic reaction for better understanding and modeling at scale.

\section{Homogeneous Systems: Direct Photolysis, $\mathrm{UVC} / \mathrm{H}_{2} \mathrm{O}_{2}$, and Photo-Fenton Processes}

Oxidation in the presence of hydrogen peroxide and ultraviolet $\mathrm{C}$ radiation $\left(\mathrm{UVC} / \mathrm{H}_{2} \mathrm{O}_{2}\right)$ is a commonly proposed AOP for wastewater treatment. The main advantage is the adoption of a relatively cheap reagent, hydrogen peroxide, for homogenous treatment with the generation of non-selective hydroxyl radicals. These efficiently mineralize a wide range of recalcitrant pollutants and their oxidized by-products. The main drawback is the adoption of UVC lamps and the necessity to ensure full degradation of hydrogen peroxide or its removal before wastewater discharge.

Intrinsic kinetic studies for the $\mathrm{UVC} / \mathrm{H}_{2} \mathrm{O}_{2}$ system in a photo-microreactor have been carried out by Russo et al. in a series of papers published over the last five years [11,23,51-53]. In this case, the reactor is substantially different from the one used for studies with immobilized solid photocatalysts. It consists of a polymeric film consisting of ten circular microcapillaries in parallel, with an average diameter of $200 \mu \mathrm{m}$ and a length of $2.2 \mathrm{~m}$. The polymeric material has a refractive index close to the one of water. In the experimental runs, the polymeric film was coiled around a cylindrical germicidal lamp emitting at $254 \mathrm{~nm}$.

\subsection{Tracer Tests}

As shown in Section 2, selection of the right model for estimation of the intrinsic kinetic constant depends on the fluid dynamics of the system, the characteristic diffusion time, and the reaction kinetics. In the case of a capillary microreactor, usually, $P e \gg 1$. However, according to the general indications provided in Section 2, in the above-mentioned capillary reactor, the aspect ratio $L / d$ is exceptionally high (magnitude $\sim 10^{4}$ ), meaning that $P e^{\prime} \ll P e$ and that diffusion in the radial direction can be considered very effective. Tracer test results showed that the reactor is far from being modeled by a pure convection laminar model, and the residence time distribution is more similar to the one of a plug flow reactor, with some degree of axial dispersion. This behavior of microchannels in laminar flow was also observed by Georget et al. [66]. In this case, the axial dispersion can be evaluated through the well-known Taylor theory, fitting experimental data with a Gaussian cumulative distribution, whose variance can be correlated to the dispersion $D$ in the system. Correlations exist depending on the magnitude of axial dispersion:

$$
\begin{gathered}
E(t)=\frac{1}{\tau} \sqrt{\frac{1}{4 \pi N_{D}}} \exp \left[-\frac{(t-\tau)^{2}}{4 \tau^{2} N_{D}}\right] \text { if }\left(N_{D}<0.01\right) \\
\left(\frac{\sigma}{\tau}\right)^{2}=2 N_{D}-2 N_{D}^{2}\left[1-\exp \left(-\frac{1}{N_{D}}\right)\right] \text { if }\left(N_{D}>0.01\right)
\end{gathered}
$$


where $E(t)$ is the Gaussian residence time distribution experimentally determined by tracing, $t$ is the experimental time, $\tau$ is the mean residence time, $\sigma$ is the standard deviation of the residence time distribution, and $N_{D}$ is defined as

$$
N_{D}=\frac{D}{u L}
$$

where $u$ is the mean velocity. Some authors define the Peclet number as the reciprocal of $N_{D}$ due to its similarity to the one defined by Equation (7). However, they are substantially different, since $D$ represents dispersion and not molecular diffusion. According to the Taylor theory, a plug flow reactor model is accurate for $N_{D}<0.01$. However, the cited paper and other studies [66] have demonstrated that a plug flow reactor (PFR) model also gives satisfactory results for values of $N_{D}<0.05$. Future research should include axial dispersion in this models to compare the results and further validate the results. Also a thorough study, should address the problem of the limiting values to distinguish between different models for the most common geometries.

Charles et al. [57] have provided a similar study for a rectangular microchannel used for heterogeneous catalysis, tracing the liquid phase. In their study, they claim that observed kinetic constant changes with the flow rate even for $N_{D} \sim 0.05$ and a PFR is not adequate. However, they also observe $D a_{I I}>1$, that most likely is the reason for apparent constants changes, because of the concentration gradient in proximity of the solid catalytic layer (Section 2).

\subsection{Optical Path Length}

As discussed in Section 2, light intensity along the channel can be considered constant or can be modeled by the Lambert-Beer law. In this case, when the light source emission is perpendicular to a rectangular channel, the optical path length can be simply assumed to be equal to the distance between the two irradiated walls of the microdevice, i.e., the height of the channel. In the case of channels of different cross-sectional shapes, the proposed solution $[23,67]$ is to estimate a mean optical path length defined as the integral mean of the cross-sectional chords in the direction perpendicular to the light irradiance. According to Figure 2, the mean optical length $\bar{l}$ is defined by:

$$
\bar{l}=\frac{\int_{a}^{b} \overline{A B}(x) d x}{b-a}
$$

which, for a circular channel, is

$$
\bar{l}=\frac{\pi d}{4}
$$

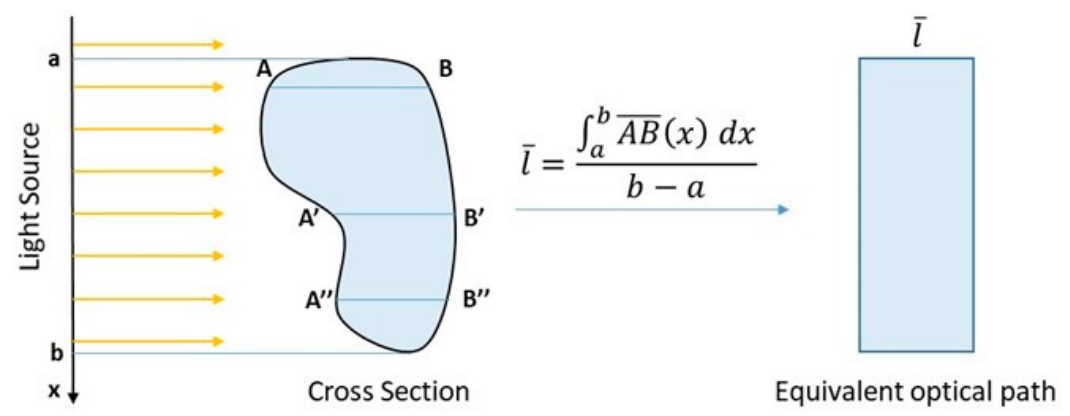

Figure 2. Geometric representation of the mean equivalent optical path.

5.3. Modeling and Validation for $\mathrm{UVC} / \mathrm{H}_{2} \mathrm{O}_{2}$ Processes

Degradation by $\mathrm{UV} / \mathrm{H}_{2} \mathrm{O}_{2}$ occurs according to the following reaction scheme:

$$
A \stackrel{h v}{\rightarrow} \text { byproducts }
$$




$$
\begin{gathered}
\mathrm{H}_{2} \mathrm{O}_{2} \stackrel{h v}{\rightarrow} 2 \mathrm{HO}^{\bullet} \\
\mathrm{HO}^{\bullet}+\mathrm{H}_{2} \mathrm{O}_{2} \stackrel{k_{\mathrm{H}}}{\rightarrow} \mathrm{H}_{2} \mathrm{O}+\mathrm{HO}_{2}^{\bullet} \\
A+\mathrm{HO}^{\bullet} \stackrel{k_{\mathrm{HO}}}{\rightarrow} \text { byproducts }+\mathrm{HO}^{\bullet} \stackrel{k_{\mathrm{HO}}}{\rightarrow} \text { byproducts... } \\
2 \mathrm{HO}_{2}^{\bullet} \rightarrow \mathrm{H}_{2} \mathrm{O}_{2}+\mathrm{O}_{2}
\end{gathered}
$$

in which direct photolysis of the substrate is also taken into account. According to this simplified scheme, by-products can be further oxidized with the same intrinsic reaction constant $k_{\mathrm{HO}}$ (r.7). A detailed mechanistic study with the identification, isolation, and investigation of by-products can be used for further detailed mechanistic models and better parameter estimation. Under these simplified assumptions, the kinetic model for the plug flow reactor assumption can be written as [52]:

$$
\begin{gathered}
\frac{d[A]}{d \tau}=-\frac{I_{254}}{V} \Phi_{U V C}^{A}\left(1-\exp \left(-2.3 \bar{l} A b s_{\text {tot }}\right)\right) \frac{\varepsilon_{U V C}^{A} \cdot[A]}{A b s_{t o t}}-\frac{2 k_{H O}[A] F_{\mathrm{H}_{2} \mathrm{O}_{2}}}{k_{\mathrm{HO}}[A]_{0}+k_{\mathrm{H}}\left[\mathrm{H}_{2} \mathrm{O}_{2}\right]} \\
\frac{d\left[\mathrm{H}_{2} \mathrm{O}_{2}\right]}{d \tau}=-F_{\mathrm{H}_{2} \mathrm{O}_{2}}-\frac{F_{\mathrm{H}_{2} \mathrm{O}_{2}} \cdot k_{\mathrm{H}} \cdot\left[\mathrm{H}_{2} \mathrm{O}_{2}\right]}{k_{\mathrm{HO}}[A]_{0}+k_{\mathrm{H}}\left[\mathrm{H}_{2} \mathrm{O}_{2}\right]}
\end{gathered}
$$

where

$$
F_{\mathrm{H}_{2} \mathrm{O}_{2}}=\frac{I_{U V C}}{V} \Phi_{U V C}^{\mathrm{H}_{2} \mathrm{O}_{2}}\left(1-\exp \left(-2.3 \bar{l} A b s_{t o t}\right)\right) \cdot \frac{\varepsilon_{U V C}^{\mathrm{H}_{2} \mathrm{O}_{2}} \cdot\left[\mathrm{H}_{2} \mathrm{O}_{2}\right]}{A b s_{t o t}}
$$

where $\frac{I_{254}}{V}$ is the incident light intensity per unit volume, $\Phi_{U V C}^{A}$ is the quantum yield of photolysis the species $A, \varepsilon_{U V C}^{A}$ is the molar absorption coefficient of the species $A,[A]_{0}$ is the initial concentration of the species $A, \Phi_{U V C}^{\mathrm{H}_{2} \mathrm{O}_{2}}$ is the quantum yield of photolysis of hydrogen peroxide, $\varepsilon_{U V C}^{\mathrm{H}_{2} \mathrm{O}_{2}}$ is the molar absorption coefficient of hydrogen peroxide, $\bar{l}$ is the mean optical path, $\tau$ is the residence time, and $A b s_{t o t}$ is the absorbance of the reacting mixture. In pure water and under the assumption that by-products have negligible molar absorption coefficients, it becomes:

$$
A b s_{t o t}=\varepsilon_{U V C}^{\mathrm{H}_{2} \mathrm{O}_{2}} \cdot\left[\mathrm{H}_{2} \mathrm{O}_{2}\right]+\varepsilon_{U V C}^{A} \cdot[A]
$$

In the presence of more mechanistic information, the above-mentioned model can be further detailed by relaxing some hypotheses. The reaction rates can be also used in full descriptive models by taking into account the influence of axial dispersion using Equation (30):

$$
u \frac{\partial[A]}{\partial x}-D \frac{\partial^{2}[A]}{\partial x^{2}}+r_{A}=0
$$

where $x$ is the axial spatial coordinate, $r_{A}$ is given by the above-mentioned equations, and $D$ is evaluated through Equations (21)-(22), reported in Section 4. At present, there are no models including axial dispersion in microreactors for the estimation of intrinsic kinetic constants for $\mathrm{UVC} / \mathrm{H}_{2} \mathrm{O}_{2}$ processes.

The above-mentioned model, under PFR assumption, was used to estimate the quantum yield of photolysis and the constants $k_{H O}$ for several micropollutants, including benzoylecgonine [23,53], acyclovir [51], stavudine, zidovudine [11], isoxazole, and isothiazolinones [52], and was validated through the estimation of parameters for known compounds such as caffeine [23]. The papers highlighted the ultrafast experimental campaigns associated with the use of this experimental set-up, allowing for exceptionally fast degradation and minimum produced waste. As an example, the entire experimental campaign for benzoylecgonine, investigating the effects of concentrations, $\mathrm{pH}$, light intensity, residence time, and aqueous matrix, took less than 2 months, with an overall use of less than $25 \mathrm{mg}$ of pollutants, the analytical part being the time bottleneck $[23,53]$. The model has also been used to model degradation in more complex aqueous matrices such as surface water, 
real wastewater, and synthetic wastewater [53]. None of these papers included microkinetic approaches, and the effect of the aqueous matrix is simply taken into account by using a simple scavenging reaction and considering the change in the total absorbance of the solutions. However, the models seemed to be adequate for a first simplified description.

Further research will have to address more detailed kinetic models, also taking into account axial dispersion, for further validation and better understanding of the effect of aqueous matrices on the degradation pattern of parent compounds as well as formed by-products.

\subsection{Modeling for Photo-Fenton Processes}

A kinetic investigation of photo-Fenton processes in a microreactor has been presented very recently [54]. In this work, the adopted experimental set-up is of the same type as the one independently used for $\mathrm{UVC} / \mathrm{H}_{2} \mathrm{O}_{2}$ investigations, but with some substantial differences. The reactor consists of a PTFE (Teflon) tube with an internal diameter of $500 \mu \mathrm{m}$, coiled on a fluorescent light. In this case, however, the refractive index of the polymer was substantially different from the one of water and it is estimated that $70 \%$ of the light from the light source could not reach the inner surface of the channel. As a result, the light dependence of the constants could not be assessed. Moreover, the larger diameter combined with the lower flow rates and the longer residence time (10-40 min) would require a further evaluation of the dispersion. Despite the fact that no tracer experiment is provided, the high aspect ratio and the long residence time allow to estimate a characteristic time of radial diffusion much smaller than diffusion in the axial direction. However, this does not exclude the presence of axial dispersion effects.

A detailed kinetic model was derived for carbofuran degradation according to the following reaction mechanism:

$$
\begin{gathered}
\mathrm{Fe}^{2+}+\mathrm{H}_{2} \mathrm{O}_{2} \rightarrow \mathrm{Fe}^{3+}+\mathrm{OH}^{-}+\mathrm{HO}^{\bullet} \\
\mathrm{Fe}^{2+}+\mathrm{HO}^{\bullet} \rightarrow \mathrm{OH}^{-}+\mathrm{Fe}^{3+} \\
\mathrm{Fe}^{2+}+\mathrm{HO}_{2}^{\bullet} \rightarrow \mathrm{Fe}^{3+}+\mathrm{HO}_{2}^{-} \\
\mathrm{Fe}^{3+}+\mathrm{H}_{2} \mathrm{O}_{2} \rightarrow \mathrm{Fe}^{2+}+\mathrm{HO}_{2}^{\bullet}+\mathrm{H}^{+} \\
\mathrm{Fe}^{3+}+\mathrm{HO}_{2}^{\bullet} \rightarrow \mathrm{Fe}^{2+}+\mathrm{O}_{2}+\mathrm{H}^{+} \\
\mathrm{H}_{2} \mathrm{O}_{2}+\mathrm{HO}^{\bullet} \rightarrow \mathrm{HO}_{2}^{\bullet}+\mathrm{H}_{2} \mathrm{O} \\
\mathrm{A}+\mathrm{HO}^{\bullet} \rightarrow \mathrm{R}\left(\mathrm{CO}_{2}\right) \\
\mathrm{Fe}^{3+}-\mathrm{R}\left(\mathrm{CO}_{2}\right) \stackrel{h v}{\rightarrow} \mathrm{Fe}^{2+}+\mathrm{R}_{\left(\mathrm{CO}_{2}\right)}
\end{gathered}
$$

and a genetic algorithm was used to estimate kinetic constants. The results were compared to the ones obtained in a batch reactor. This is the first reported kinetic investigation of photoFenton processes with low iron concentrations in microreactors. Nonetheless, future efforts should address the issue of the light dependence of the constants for a more reliable and scalable estimation of the parameters.

\section{By-Products and Intermediates' Determination}

Identification and quantification of by-products and intermediates formed during degradation of pollutants are of crucial importance for the following reasons:

(i) They can help to build more comprehensive detailed kinetic models, also taking into account their relative effect on the overall degradation process. Some of the formed intermediates, in fact, may act as scavengers, significantly change absorption of the fluid, change the adsorption state of solid catalysts' surfaces, etc.;

(ii) They can show worse eco-toxicological responses, both acute and chronic, than their parent compounds; 
(iii) Treatment unit sizing — the required time for complete removal of toxic species might be much longer than the time to fully remove the target parent compound.

Tsuchiya et al. [60] have highlighted that as a result of the high surface-to-volume ratio typical of microdevices, intermediates are present at higher concentrations in these systems. This makes microreactors particularly suitable for the identification crucial species that can be formed at very low concentrations at lab macro scale or at pilot or full scale. Another main advantage is that this type of continuous flow microdevice can be easily coupled with automated analytical tools, i.e., GC, LC, MS, etc., for the determination of intermediates in a fully automated fashion [27-29]. Despite this, the number of studies making use of microreactors for intermediates' identification in AOPs for wastewater treatment is still relatively low.

Using a $\mathrm{TiO}_{2}$ catalyst, the intermediates in the degradation of six dyes [60], Diuron [50], and phenol [42] were identified and quantified by coupling microreactors with LC-MS/MS analysis. The results were used in some cases to propose detailed mechanisms and develop full kinetic models.

Azzouz et al. [68] studied the degradation of several target pollutants using $\mathrm{ZnO}$ nanowires in a microreactor and used GC analysis to elucidate the chemical nature of the formed by-products.

Finally, in the case of homogeneous processes, intermediates generated by $\mathrm{UV}-\mathrm{C} / \mathrm{H}_{2} \mathrm{O}_{2}$ were identified for benzoylecgonine and benzisothiazolinone [52,69] using LC-MS/MS analysis and samples generated during kinetic investigation with a microcapillary photoreactor. Samples easily generated at different reaction times by using the above-mentioned experimental set-up were also used to investigate eco-toxicological effects on target aquatic organisms [11,51,53], demonstrating that toxic degradation products can persist in treated water even when the target compounds are fully degraded, and longer residence times are needed to reduce eco-toxicological responses.

\section{Conclusions}

Micro- and photo-microreactors are unlikely to be directly used for water treatment, but they can be extremely powerful experimental tools for better understanding of the intrinsic kinetics of pollutant degradation. In the field of AOPs, this is of crucial importance to bridge the existing gap between the results of experimental campaigns at lab scale and the design of processes at full scale.

Despite the wide reported use of microreactors for catalytic processes' screening and preliminary kinetic investigations, still, a relatively small number of papers are addressing the use of these devices to gain fundamental knowledge on this processes that could be transferable across scales; this is mainly related to intrinsic kinetic parameters' dependence on operating conditions, generated by-products, and their eco-toxicological effects.

The determination of intrinsic kinetic parameters can only be realized if a proper model for microdevices is identified, based on the relative magnitude of the different mechanisms controlling the overall degradation process. Coupling fully characterized devices with automated in-line and on-line analytics would allow for a fast, safe, reliable, and cheap assessment of several compounds' degradation, by-products identification, and collection of samples for further ecotoxicological assessments.

With the increase in commercially available treatment-recalcitrant compounds discharged daily to surface water, more stringent regulations will be expected for their levels in wastewater. As a result, the adoption of AOPs as tertiary treatment units and fast experimental campaigns for their design are likely to become a necessity in the near future. In this regard, the development of microdevices for efficient and cheap fundamental investigations might represent a promising alternative to traditional batch investigations.

Future research will have to focus on the use of microreactors to gain fundamental knowledge on the above-mentioned revised AOPs, as well as innovative technologies never investigated in microreactors before such as supercritical water oxidation, sonolysis, electron beam irradiation, and photosensitization. 
Further challenges to be addressed will also be represented by standardization and democratization of such devices and software for their control and modeling, together with their integration in cheap "plug-and-play" systems, which would enable a large number of operators with different expertise levels to collect the information required for a conscious development of AOPs at full scale.

Funding: This research received no external funding.

Institutional Review Board Statement: Not applicable.

Informed Consent Statement: Not applicable.

Data Availability Statement: Data sharing not applicable.

Acknowledgments: The author is grateful to Raffaele Marotta for his help with proofreading.

Conflicts of Interest: The authors declare no conflict of interest.

\section{References}

1. Luo, Y.; Guo, W.; Ngo, H.H.; Nghiem, L.D.; Hai, F.I.; Zhang, J.; Liang, S.; Wang, X.C. A review on the occurrence of micropollutants in the aquatic environment and their fate and removal during wastewater treatment. Sci. Total Environ. 2014, 473-474, 619-641. [CrossRef] [PubMed]

2. Margot, J.; Rossi, L.; Barry, D.A.; Holliger, C. A review of the fate of micropollutants in wastewater treatment plants. Wires Water 2015, 2, 457-487. [CrossRef]

3. Rogowska, J.; Cieszynska-Semenowicz, M.; Ratajczyk, W.; Wolska, L. Micropollutants in treated wastewater. Ambio 2020, 49, 487-503. [CrossRef] [PubMed]

4. $\quad$ Eggen, R.I.L.; Hollender, J.; Joss, A.; Scharer, M.; Stamm, C. Reducing the discharge of micropollutants in the aquatic environment: The benefits of upgrading wastewater treatment plants. Environ. Sci. Technol. 2014, 48, 7683-7689. [CrossRef]

5. Gomes, J.; Domingues, E.; Gmurek, M.; Quinta-Ferreira, R.M.; Martins, R.C. Advanced oxidation processes for recalcitrant compounds removal comparison with biofiltration by Corbicula fluminea. Energy Rep. 2020, 6, 666-671. [CrossRef]

6. Ghatak, H.R. Advanced oxidation processes for the treatment of biorecalcitrant organics in wastewater. Crit. Rev. Environ. Sci. Technol. 2014, 44, 1167-1219. [CrossRef]

7. Andreozzi, R.; Caprio, V.; Insola, A.; Marotta, R. Advanced oxidation processes (AOP) for water purification and recovery. Catal. Today 1999, 53, 51-59. [CrossRef]

8. Cuerda-Correa, E.M.; Alexandre-Franco, M.F.; Fernandez-Gonzalez, C. Advanced oxidation processes for the removal of antibiotics from water. An overview. Water 2020, 12, 102. [CrossRef]

9. Suhadolnik, L.; Pohar, A.; Novak, U.; Likozar, B.; Mihelic, A.; Čeh, M. Continuous photocatalytic, electrocatalytic and photoelectrocatalytic degradation of a reactive textile dye for wastewater-treatment processes: Batch, microreactor and scaled-up operation. J. Ind. Eng. Chem. 2019, 72, 178-188. [CrossRef]

10. Casado, C.; Marugan, J.; Timmers, R.; Munoz, M.; van Grieken, R. Comprehensive multiphysics modelling of photocatalytic processes by computational fluid dynamics based on intrinsic kinetic parameters determined in a differential photoreactor. Chem. Eng. J. 2017, 310, 368-380. [CrossRef]

11. Russo, D.; Siciliano, A.; Guida, M.; Andreozzi, R.; Reis, N.M.; Li Puma, G.; Marotta, R. Removal of antiretroviral drugs stavudine and zidovudine in water under $\mathrm{UV}_{254}$ and $\mathrm{UV}_{254} / \mathrm{H}_{2} \mathrm{O}_{2}$ processes: Quantum yields, kinetics and ecotoxicology assessment. J. Hazard. Mater. 2018, 349, 195-204. [CrossRef] [PubMed]

12. Visan, A.; Rafieian, D.; Ogieglo, W.; Lammertink, R.G.H. Modeling intrinsic kinetics in immobilized photocatalytic microreactors. Appl. Catal. B Environ. 2014, 150-151, 93-100. [CrossRef]

13. Leyva, E.; Moctezuma, E.; Baines, K.M.; Noriega, S.; Zarazua, E. A review on chemical advanced oxidation processes for pharmaceuticals with paracetamol as a model compound. Reaction conditions, intermediates and total mechanism. Curr. Org. Chem. 2018, 22, 2-17. [CrossRef]

14. Zhang, T.; Cheng, L.; Ma, L.; Meng, F.; Arnold, R.G.; Saez, A.E. Modeling the oxidation of phenolic compounds by hydrogen peroxide photolysis. Chemosphere 2016, 161, 349-357. [CrossRef]

15. Jeong, J.; Jung, J.; Cooper, W.J.; Song, W. Degradation mechanisms and kinetic studies for the treatment of X-ray contrast media compounds by advanced oxidation/reduction processes. Water Res. 2010, 44, 4391-4398. [CrossRef]

16. Oller, I.; Malato, S.; Sanchez-Perez, J.A. Combination of advanced oxidation processes and biological treatments for wastewater decontamination-A review. Sci. Total Environ. 2011, 409, 4141-4166. [CrossRef]

17. Alharbi, S.K.; Price, W.E. Degradation and fate of pharmaceutically active contaminants by advanced oxidation processes. Curr. Pollution Rep. 2017, 3, 268-280. [CrossRef]

18. Rizzo, L. Bioassays as a tool for evaluating advanced oxidation processes in water and wastewater treatment. Water Res. 2011, 45, 4311-4340. [CrossRef] 
19. Siciliano, A.; Russo, D.; Spasiano, D.; Marotta, R.; Race, M.; Fabbricino, M.; Galdiero, E.; Guida, M. Chronic toxicity of treated and untreated aqueous solutions containing imidazole-based ionic liquids and their oxydized by-products. Ecotox. Environ. Safe. 2019, $180,466-472$.

20. Zeghioud, H.; Khellaf, N.; Djelal, H.; Amrane, A.; Bouhelassa, M. Photocatalytic reactors dedicated to the degradation of hazardous organic pollutants: Kinetics, mechanistic aspects, and design-A review. Chem. Eng. Commun. 2016, 203, $1415-1431$. [CrossRef]

21. Sundar, K.P.; Kanmani, S. Progression of photocatalytic reactors and it's comparison: A review. Chem. Eng. Res. Des. 2020, 154, 135-150. [CrossRef]

22. Heggo, D.; Ookawara, S. Multiphase photocatalytic microreactors. Chem. Eng. Sci. 2017, 169, 67-77. [CrossRef]

23. Russo, D.; Spasiano, D.; Vaccaro, M.; Andreozzi, R.; Li Puma, G.; Reis, N.M.; Marotta, R. Direct photolysis of benzoylecgonine under UV irradiation at $254 \mathrm{~nm}$ in a continuous flow microcapillary array photoreactor. Chem. Eng. J. 2016, 283, 243-250. [CrossRef]

24. Zhan, X.; Yan, C.; Zhang, Y.; Rinke, G.; Rabsch, G.; Klumpp, M.; Schafer, A.I.; Dittmeyer, R. Investigation of the reaction kinetics of photocatalytic pollutant degradation under defined conditions with inkjet-printed $\mathrm{TiO}_{2}$ films-From batch to a novel continuous-flow microreactor. React. Chem. Eng. 2020, 5, 1658-1670. [CrossRef]

25. Wang, N.; Zhang, X.; Wang, Y.; Yu, W.; Chan, H.L.W. Microfluidic reactors for photocatalytic water purification. Lab. Chip 2014, 14, 1074-1082. [CrossRef] [PubMed]

26. Tokode, O.; Prabhu, R.; Lawton, L.A.; Robertson, P.K.J. UV LED sources for heterogeneous photocatalysis. In Environmental Photochemistry Part. III; The Handbook of Environmental Chemistry book series; Springer: Berlin/Heidelberg, Germany, 2014; Volume 35, pp. 159-179.

27. McMullen, J.P.; Jensen, K.F. Integrated microreactors for reaction automation: New approaches to reaction development. Annu. Rev. Anal. Chem. 2010, 3, 19-42. [CrossRef]

28. Trojanowicz, M. Flow chemistry in contemporary chemical sciences: A real variety of its applications. Molecules 2020, 25, 1434. [CrossRef]

29. Aroh, K.C.; Jensen, K.F. Efficient kinetic experiments in continuous flow microreactors. React. Chem. Eng. 2018, 3, 94. [CrossRef]

30. Alimi, O.A.; Akinnawo, C.A.; Onisuru, O.R.; Meijboom, R. 3-D printed microreactor for continuous flow oxidation of a flavonoid. J. Flow Chem. 2020, 10, 517-531. [CrossRef]

31. Zhang, H.; Wang, J.J.; Fan, J.; Fang, Q. Microfluidic chip-based analytical system for rapid screening of photocatalysts. Talanta 2013, 116, 946-950. [CrossRef]

32. Zhang, Q.; Zhang, Q.; Wang, H.; Li, Y. A high efficiency microreactor with $\mathrm{Pt} / \mathrm{ZnO}$ nanorod arrays on the inner wall for photodegradation of phenol. J. Hazard. Mater. 2013, 254-255, 318-324. [CrossRef] [PubMed]

33. Rahimi, M.; Aghel, B.; Sadeghi, M.; Ahmadi, M. Using Y-shaped microreactor for continuous decolorization of an Azo dye. Desalination Water Treat. 2014, 52, 5513-5519. [CrossRef]

34. Ramos, B.; Ookawara, S.; Matsushita, Y.; Yoshikawa, S. Intensification of photochemical wastewater decolorization process using microreactor. J. Chem. Eng. Jpn 2014, 47, 136-140. [CrossRef]

35. Teekateerawej, S.; Nishino, J.; Nosaka, Y. Design and evaluation of photocatalytic micro-channel reactors using $\mathrm{TiO}_{2}$-coated porous ceramics. J. Photoch. Photobio. A 2006, 179, 263-268. [CrossRef]

36. Meng, Z.; Zhang, X.; Qin, J. A high efficiency microfluidic-based photocatalytic microreactor using electrospun nanofibrous $\mathrm{TiO}_{2}$ as a photocatalyst. Nanoscale 2013, 5, 4687. [CrossRef]

37. Lu, X.; Li, Z.; Liu, Y.; Tang, B.; Zhu, Y.; Razal, J.M.; Pakdel, E.; Wang, J.; Wang, X. Titanium dioxide coated carbon foam as microreactor for improved sunlight driven treatment of cotton dyeing wastewater. J. Clean. Prod. 2020, 246, 118949. [CrossRef]

38. Lamberti, A. Microfluidic photocatalytic device exploting $\mathrm{PDMS}_{\mathrm{T}} \mathrm{TiO}_{2}$ nanocomposite. Appl. Surf. Sci. 2015, 335, 50-54. [CrossRef]

39. Li, Y.; Lin, B.; Ge, L.; Guo, H.; Chen, X.; Lu, M. Real-time spectroscopic monitoring of photocatalytic activity promoted by graphene in a microfluidic reactor. Sci. Rep. 2016, 6, 28803. [CrossRef]

40. Yusuf, A.; Palmisano, G. Three-dimensional CFD modelling of a photocatalytic parallel-channel microreactor. Chem. Eng. Sci. 2021, 229, 116051. [CrossRef]

41. Li, L.; Tang, D.; Song, Y.; Jiang, B. Dual-film optofluidic microreactor with enhanced light-harvesting for photocatalytic applications. Chem. Eng. J. 2018, 339, 71-77. [CrossRef]

42. de Sá, D.S.; Vasconcellos, L.E.; de Souza, J.R.; Marinkovic, B.A.; Del Rosso, T.; Fulvio, D.; Maza, D.; Massi, A.; Pandoli, O. Intensification of photocatalytic degradation of organic dyes and phenol by scale-up and numbering-up of meso- and microfluidic $\mathrm{TiO}_{2}$ reactors for wastewater treatment. J. Photochem. Photobiol. A 2018, 364, 59-75. [CrossRef]

43. Rafieian, D.; Driessen, R.T.; Ogieglo, W.; Lammertink, G.H. Intrinsic Photocatalytic Assessment of Reactively Sputtered TiO 2 Films. Appl. Mater. Interfaces 2015, 7, 8727-8732. [CrossRef] [PubMed]

44. Satuf, M.L.; Macagno, J.; Manassero, A.; Bernal, G.; Kler, P.A.; Berli, C.L.A. Simple method for the assessment of intrinsic kinetic constants in photocatalytic microreactors. Appl. Catal. B 2019, 241, 8-17. [CrossRef]

45. Visan, A.; Ruud van Ommen, J.; Kreutzer, M.T.; Lammertink, R.G.H. Photocatalytic reactor design: Guidelines for kinetic investigation. Ind. Eng. Chem. Res. 2019, 58, 5349-5357. [CrossRef] 
46. Suhadolnik, L.; Jukovic, D.L.; Likozar, B.; Bele, M.; Drev, S.; Ceh, M. Structured titanium oxynitride (TiOxNy) nanotube arrays for a continuous electrocatalytic phenol-degradation process: Synthesis, characterization, mechanisms and the chemical reaction micro-kinetics. Appl. Catal. B 2019, 257, 117894. [CrossRef]

47. Gorges, R.; Meyer, S.; Kreisel, G. Photocatalysis in microreactors. J. Photoch. Photobio. A 2004, 167, 95-99. [CrossRef]

48. Lindstrom, H.; Wootton, R.; Iles, A. High surface area titania photocatalytic microfluidic reactors. AIChE J. 2007, 53, 695-702. [CrossRef]

49. Corbel, S.; Charles, G.; Becheikh, N.; Roques-Carmes, T.; Zahraa, O. Modelling and design of microchannel reactor for photocatalysis. Virtual Phys. Prototyp. 2012, 7, 203-209. [CrossRef]

50. Khongthon, W.; Jovanovic, G.; Yokochi, A.; Sangvanich, P.; Pavarajarn, V. Degradation of diuron via an electrochemical advanced oxidation process in a microscale-based reactor. Chem. Eng. J. 2016, 292, 298-307. [CrossRef]

51. Russo, D.; Siciliano, A.; Guida, M.; Galdiero, E.; Amoresano, A.; Andreozzi, R.; Reis, N.M.; Li Puma, G.; Marotta, R. Photodegradation and ecotoxicology of acyclovir in water under $\mathrm{UV}_{254}$ and $\mathrm{UV}_{254} / \mathrm{H}_{2} \mathrm{O}_{2}$ processes. Water Res. 2017, 122, 591-602. [CrossRef]

52. Russo, D.; Cochran, K.H.; Westerman, D.; Li Puma, G.; Marotta, R.; Andreozzi, R.; Richardson, S.D. Ultrafast photodegradation of isoxazole and isothiazolinones by $\mathrm{UV}_{254}$ and $\mathrm{UV}_{254} / \mathrm{H}_{2} \mathrm{O}_{2}$ photolysis in a microcapillary reactor. Water Res. 2020, $169,115203$. [CrossRef] [PubMed]

53. Spasiano, D.; Russo, D.; Vaccaro, M.; Siciliano, A.; Marotta, R.; Guida, M.; Reis, N.M.; Li Puma, G.; Andreozzi, R. Removal of benzoylecgonine from water matrices through $\mathrm{UV}_{254} / \mathrm{H}_{2} \mathrm{O}_{2}$ process: Reaction kinetic modeling, ecotoxicity and genotoxicity assessment. J. Hazard. Mater. 2016, 318, 515-525. [CrossRef] [PubMed]

54. Shinozawa, Y.; Heggo, D.; Ookawara, S.; Yoshikawa, S. Photo-Fenton Degradation of Carbofuran in Helical Tube Microreactor and Kinetic Modeling. Ind. Eng. Chem. Res. 2020, 59, 3811-3819. [CrossRef]

55. Das, S.; Srivastava, V.C. Microfluidic-based photocatalytic microreactor for environmental application: A review of fabrication substrates and techniques, and operating parameters. Photochem. Photobiol. Sci. 2016, 15, 714-730. [CrossRef]

56. Sohrabi, S.; Moraveji, M.K.; Iranshahi, D. A review on the design and development of photocatalyst synthesis and application in microfluidic reactors: Challenges and opportunities. Rev. Chem. Eng. 2019, 36, 1-35. [CrossRef]

57. Charles, G.; Roques-Carmes, T.; Becheikh, N.; Falk, L.; Commenge, J.M.; Corbel, S. Determination of kinetic constants of a photocatalytic reaction in micro-channel reactors in the presence of mass-transfer limitation and axial dispersion. J. Photoch. Photobio. A 2011, 223, 202-211. [CrossRef]

58. Krivec, M.; Zagar, K.; Suhadolnik, L.; Ceh, M.; Drazic, G. Highly Efficient $\mathrm{TiO}_{2}$-Based Microreactor for Photocatalytic Applications. Appl. Mater. Interfaces 2013, 5, 9088-9094. [CrossRef]

59. Matsushita, Y.; Ohba, N.; Kumada, S.; Sakeda, K.; Suzuki, T.; Ichimura, T. Photocatalytic reactions in microreactors. Chem. Eng. J. 2008, 135S, S303-S308. [CrossRef]

60. Tsuchiya, N.; Kuwabara, K.; Hidaka, A.; Oda, K.; Katayama, K. Reaction kinetics of dye decomposition processes monitored inside a photocatalytic microreactor. Phys. Chem. Chem. Phys. 2012, 14, 4734-4741. [CrossRef]

61. Yu, G.; Wang, N. Gas-Liquid-Solid interface enhanced photocatalytic reaction in a microfluidic reactor for water treatment. Appl. Catal. A 2020, 591, 117410. [CrossRef]

62. Muddemann, T.; Haupt, D.; Sievers, M.; Kunz, U. Electrochemical reactors for wastewater treatment. ChemBioEng Rev. 2019, 6, 142-156. [CrossRef]

63. Martinez-Huitle, C.A.; Panizza, M. Electrochemical oxidation of organic pollutants for wastewater treatment. Curr. Opin. Electrochem. 2018, 11, 62-71. [CrossRef]

64. He, X.; Chen, R.; Zhu, X.; Liao, Q.; An, L.; Cheng, X.; Li, L. Optofluidics-Based Membrane Microreactor for Wastewater Treatment by Photocatalytic Ozonation. Ind. Eng. Chem. Res. 2016, 55, 8627-8635. [CrossRef]

65. Cao, Q.; Sang, L.; Tu, J.; Xiao, Y.; Liu, N.; Wu, L.; Zhang, J. Rapid degradation of refractory organic pollutants by continuous ozonation in a micro-packed bed reactor. Chemosphere 2020, in press. [CrossRef] [PubMed]

66. Georget, E.; Sauvageat, J.L.; Burbidge, A.; Mathys, A. Residence time distributions in a modular micro reaction system. J. Food Eng. 2013, 116, 910-919. [CrossRef]

67. Russo, D.; Tammaro, M.; Salluzzo, A.; Andreozzi, R.; Marotta, R. Modeling and validation of a modular multi-lamp photo-reactor for cetylpyridinium chloride degradation by $\mathrm{UV}$ and $\mathrm{UV} / \mathrm{H}_{2} \mathrm{O}_{2}$ processes. Chem. Eng. J. 2019, 376, 120380. [CrossRef]

68. Azzouz, I.; Habba, Y.G.; Capochichi-Gnambodoe, M.; Marty, F.; Vial, J.; Leprince-Wang, Y.; Bourouina, T. Zinc oxide nano-enabled microfluidic reactor for water purification and its applicability to volatile organic compounds. Microsyst. Nanoeng. 2018, 4, 17093. [CrossRef]

69. Russo, D.; Spasiano, D.; Vaccaro, M.; Cochran, K.H.; Richardson, S.D.; Andreozzi, R.; Li Puma, G.; Reis, N.M.; Marotta, R. Investigation on the removal of the major cocaine metabolite (benzoylecgonine) in water matrices by $\mathrm{UV}_{254} / \mathrm{H}_{2} \mathrm{O}_{2}$ process by using a flow microcapillary film array photoreactor as an efficient experimental tool. Water Res. 2016, 89, 375-383. [CrossRef] 